\title{
Aplikasi Model Indeks Tunggal dalam Pembentukan Portofolio Optimal pada Data Harga Saham Indeks IDX30 di Bursa Efek Indonesia
}

\author{
Rahmi Oktavia Maudinatul ${ }^{*}$ \\ Prodi Statistika, Fakultas Matematika dan Ilmu Pengetahuan Alam, \\ Universitas Islam Bandung, Indonesia. \\ *rahmioktaviabkl@gmail.com
}

\begin{abstract}
The purpose of this study is to identify and analyze stocks that are included in the optimal portfolio on the IDX30 Index on the Indonesia Stock Exchange (IDX), the proportion of funds and the level of profit for each stock that can form a single index model for the optimal portfolio. The research method used is descriptive with a quantitative approach. The object of this research is secondary data, namely stock prices listed on the IDX30 Index in the period September 2014 - January 2021. The results of this study using a single index model show that from 30 companies there are 11 preferred stocks and the proportion of funds for each share is the value of the proportion the highest fund is BBCA of Rp. 30,025,989 and the lowest proportion of funds is BBTN of Rp. 845,917. Analysis of the level of expected return portfolio that will be obtained by investors is $2.52 \%$ and the risk level of the stock portfolio is $1.86 \%$.
\end{abstract}

Keywords: IDX30 Index, Single Index Model, Optimal Portfolio.

Abstrak. Tujuan penelitian ini untuk mengetahui dan menganalisa saham-saham yang termasuk portofolio optimal pada Indeks IDX30 di Bursa Efek Indonesia (BEI), proporsi dana serta tingkat keuntungan pada masing-masing saham yang dapat membentuk model indeks tunggal portofolio optimal. Metode penelitian yang digunakan adalah deskriptif dengan pendekatan kuantitatif. Objek penelitian ini berupa data sekunder yaitu harga saham yang terdaftar pada Indeks IDX30 pada periode September 2014 - Januari 2021. Hasil penelitian ini dengan menggunakan model indeks tunggal menunjukkan bahwa dari 30 perusahaan terdapat 11 saham pilihan dan didapatkan proporsi dana masing-masing saham yaitu nilai proporsi dana tertinggi adalah BBCA sebesar Rp. 30.025.989 dan nilai proporsi dana terendah adalah BBTN sebesar Rp. 845.917. analisis tingkat expected return portofolio yang akan diperoleh oleh investor yaitu sebesar 2,52\% dan tingkat risiko portofolio saham yaitu sebesar $1,86 \%$.

Kata Kunci: Indeks IDX30, Model Indeks Tunggal, Portofolio Optimal. 


\section{A. Pendahuluan}

Pasar modal (capital market) merupakan pasar untuk berbagai instrumen keuangan jangka panjang yang bisa diperjualbelikan, seperti surat utang (obligasi), ekuiti (saham), reksa- dana, instrumen derivatif maupun instrumen lainnya. Pasar modal menjadikan sarana pendanaan bagi perusahaan maupun institusi lain (misalnya pemerintah), dan sebagai sarana bagi kegiatan berinvestasi. Dengan demikian, pasar modal memfasilitasi berbagai sarana dan prasarana kegiatan jual beli dan kegiatan terkait lainnya (Bursa Efek Indonesia, 2021).

Dapat dilihat dari perkembangan pasar modal di Indonesia yaitu pertumbuhan sektor seperti indeks IDX30. Indeks IDX30 adalah indeks yang mengukur kinerja harga dari 30 saham yang terdaftar dan diseleksi berdasarkan beberapa kriteria yang memiliki likuiditas tinggi di Bursa Efek Indonesia (BEI) dan kapitalisasi pasar besar serta didukung oleh fundamental perusahaan yang baik. Pada dasarnya, perkembangan pasar modal yang baik disuatu negara tercermin dari tingginya jumlah saham yang diperdagangkan, jumlah perusahaan (emiten) yang terdaftar, volume transaksi, nilai transaksi, dan Indeks Harga Saham Gabungan (IHSG), serta nilai kapitalisasi pasar yang semuanya itu telah membawa konsekuensi tertentu bagi para investor (penanam modal), emiten, dan pelaku pasar modal lainnya (Sudirman, 2015).

Berdasarkan latar belakang yang telah dijelaskan di atas, maka dapat dirumuskan masalah-masalah yang akan diteliti pada penelitian ini adalah sebagai berikut: "Seberapa besar tingkat proporsi dana yang terdapat dari masing-masing saham yang dapat membentuk model indeks tunggal portofolio optimal serta tingkat keuntungannya pada indeks IDX30 di Bursa Efek Indonesia?". Selanjutnya tujuan yang akan dicapai dalam penelitian ini adalah untuk mengetahui proporsi dana yang terdapat dari masing-masing saham yang dapat membentuk model indeks tunggal portofolio optimal serta tingkat keuntungannya pada indeks IDX30 di Bursa Efek Indonesia.

\section{B. Metodologi}

Jenis data penelitian ini berupa data sekunder yang diperoleh dari sumber website resmi dengan kebenaran data yang akurat meliputi www.yahoofinance.co.id, www.idx.co.id, dan www.bi.go.id. Data yang diambil untuk keperluan penelitian ini berupa daftar harga saham yang termasuk dalam indeks IDX30 dimulai tanggal 1 September 2014 - 31 Januari 2021, penghitungan indeks IDX30 yang diambil pada periode November 2020 - Januari 2021 dan laporan bulanan data suku bunga SBI (Sertifikat Bank Indonesia) dimulai pada bulan September 2014 - Januari 2021. Teori dan metode berdasarkan penelitian ini yaitu, Model Indeks Tunggal.

Pasar modal (Capital market) merupakan pasar untuk berbagi instrumen keuangan jangka panjang yang bisa diperjualbelikan, baik surat utang (obligasi), (ekuiti) saham, reksa dana, instrumen derivatif maupun instrumen lainnya. Undang-Undang pasar modal No. 8 Tahun 1995 tentang pasar modal mendefinisikan pasar modal sebagai kegiatan yang bersangkutan dengan penawaran umum dan perdagangan efek, perusahaan publik yang berkaitan dengan efek yang diterbitkannya, serta lembaga dan profesi yang berkaitan dengan efek (Muklis Faiza, 2016).

Saham (stock) merupakan salah satu instrumen pasar modal yang paling popular atau banyak diminati. Menurut (Tannadi Belvin, 2019), saham adalah bagian kepemilikan suatu perusahaan. Kepemilikan tersebut meliputi keseluruhan aset kepemilikan suatu perusahaan yang didalamnya tercantum nilai nominal, nama perusahaan, dan diikuti dengan hak dan kewajiban yang dijelaskan kepada setiap pemegangnya.

Investasi adalah komitmen atas sejumlah dana atau sumber daya lainnya yang dilakukan pada saat ini, dengan tujuan memperoleh sejumlah keuntungan di masa datang. Seorang investor membeli sejumlah saham saat ini dengan harapan memperoleh keuntungan dari kenaikan harga saham ataupun sejumlah deviden di masa yang akan datang, sebagai imbalan atas waktu dan risiko yang terkait dengan investasi tersebut. Istilah investasi bisa berkaitan dengan berbagai macam aktivitas. Menginvestasikan sejumlah dana pada aset riil (tanah, emas, mesin atau bangunan), maupun aset finansial (deposito, saham ataupun obligasi) merupakan aktivitas investasi yang umumnya dilakukan (Handini Sri, 2020).

Investor yang berinvestasi dalam bentuk saham, otomatis akan memiliki banyak keuntungan misalnya hak kepemilikan dalam suatu perusahaan dan return saham di masa 
mendatang. Banyak sedikitnya saham yang dibeli oleh investor akan menentukan presentase kepemilikan investor tersebut dalam suatu perusahaan yang menerbitkan saham tersebut (Yulia, 2016).

Hubungan risiko dan return yang diharapkan dari suatu investasi merupakan hubungan yang searah dan linier. Artinya semakin besar risiko yang harus ditanggung, semakin besar pula tingkat return yang diharapkan (Paramitasari dan Mulyono, 2015).

Menurut (Tandelilin, 2001) Portofolio efisien adalah portofolio yang menyediakan return maksimal bagi investor dengan tingkat return tertentu. Sedangkan portofolio optimal adalah portofolio yang dipilih investor dari sekian banyak pilihan yang ada pada portofolio efisien. Dalam pembentukan portofolio investor selalu ingin memaksimalkan return yang diharapkan dengan tingkat risiko tertentu yang bersedia ditanggungnya atau mencari portofolio yang menawarkan risiko terendah dengan tingkat return tertentu. Karakteristik portofolio seperti ini disebut sebagai portofolio yang efisien.

Indeks saham adalah ukuran statistik yang mencerminkan keseluruhan pergerakan harga atas sekumpulan saham yang dipilih berdasarkan kriteria dan metodologi tertentu serta dievaluasi secara berkala. Indeks saham merupakan hal yang sangat penting untuk mendukung perkembangan pasar modal Indonesia. Indeks saham dapat digunakan untuk menjadi tolak ukur kinerja pasar modal dan produk investasi. Indeks IDX30 yaitu indeks yang mengukur kinerja harga dari 30 saham yang memiliki likuiditas tinggi dan kapitalisasi pasar besar serta didukung oleh fundamental perusahaan yang baik.

Single index model atau model indeks tunggal merupakan sebuah teknik untuk mengukur return dan risiko sebuah saham atau portofolio. Model tersebut mengasumsikan bahwa pergerakan return saham hanya berhubungan dengan pergerakan pasar. Sensitifitas pergerakan return saham terhadap pergerakan return saham terhadap pergerakan return pasar diukur dengan Beta. Tahapan analisis data dalam pembentukan portofolio optimal dengan model indeks tunggal secara berurutan langkah-langkah sebagai berikut:

1. Menghitung nilai realized return $\left(R_{i t}\right)$ dan expected return $\left(E\left(R_{i t}\right)\right)$ masing-masing saham setiap bulannya dengan rumus:

a. Realized return $\left(\mathrm{R}_{\mathrm{i}}\right)$ :

b. Expected return $\left(E\left(R_{i t}\right)\right)$ :

$$
R_{i t}=\frac{P_{i t}-P_{i(t-1)}}{P_{i(t-1)}}
$$

$$
E\left(R_{i t}\right)=\frac{\sum_{i=1}^{n} R_{i t}}{n}
$$

2. Menghitung nilai realized return pasar $\left(\mathrm{R}_{\mathrm{M}}\right)$ dan expected return $\left(\mathrm{E}\left(\mathrm{R}_{\mathrm{M}}\right)\right)$ berdasarkan IHSG bulanan.

a. Realized return pasar $\left(\mathrm{R}_{\mathrm{M}}\right)$ :

$$
R_{M t}=\frac{I H S G_{M t}-I H S G_{M(t-1)}}{I H S G_{M(t-1)}}
$$

b. Expected return pasar $\left(\mathrm{E}\left(\mathrm{R}_{\mathrm{M}}\right)\right)$

$$
E\left(R_{M}\right)=\frac{\sum_{m=1}^{n} R_{M t}}{n}
$$

3. Menghitung beta dan alpha masing-masing saham

a. Beta dengan rumus:

$$
\beta_{i}=\frac{\sigma_{i m}}{\sigma_{m}^{2}}
$$

Dimana: 


$$
\begin{gathered}
\left(\sigma_{i m}\right)=\frac{\sum_{i=1}^{n}\left[\left(R_{i t}-E\left(R_{i t}\right)\right) \cdot\left(R_{M}-E\left(R_{M}\right)\right)\right]}{n} \\
\sigma_{m}^{2}=\frac{\sum_{i=1}^{n}\left[\left(R_{i t}-E\left(R_{i t}\right)\right) \cdot\left(R_{M}-E\left(R_{M}\right)\right)\right]}{n}
\end{gathered}
$$

b. Alpha dengan rumus:

$$
\alpha_{i}=E\left(R_{i}\right)-\left[\beta_{i} . E\left(R_{M}\right)\right]
$$

4. Menghitung risiko investasi

a. Risiko tidak sistematis

$$
\sigma_{e i}^{2}=\frac{\sum_{i=1}^{n}\left(e_{i}\right)^{2}}{n}
$$

Dimana $e_{i}$ dapat dihitung dengan rumus:

b. Risiko sistematis

$$
e_{i}=R_{i t}-\left[\alpha_{i}+\left(\beta_{i} \cdot R_{M}\right)\right]
$$

$$
e_{i}=\beta_{i}^{2} \sigma_{M}^{2}+\sigma_{e i}^{2}
$$

5. Menentukan return bebas risiko

Saham yang memiliki $E\left(R_{i t}\right)>R_{B R}$ akan dimasukkan dalam analisis selanjutnya karena akan menghasilkan ERB yang positif. Investasi pada aset berisiko (saham) akan lebih menarik jika dibandingkan dengan investasi pada aset bebas risiko. Hal ini menunjukkan bahwa jika saham yang memiliki nilai tingkat keuntungan yang diharapkan lebih kecil maka saham tersebut diabaikan karena akan memperoleh nilai ERB negatif.

6. Menghitung excess return to beta (ERB)

Excess return terhadap beta (ERB) yaitu selisih dari nilai tingkat keuntungan yang diharapkan $\left(E\left(R_{i}\right)\right)$ dengan return asset bebas risiko. Nilai ERB digunakan sebagai dasar untuk menentukan saham yang masuk dalam portofolio optimal. Untuk menghitung excess return to beta (ERB) yaitu sebagai berikut:

$$
E R B_{i}=\frac{E\left(R_{i}\right)-R_{B R}}{\beta_{i}}
$$

7. Mengurutkan nilai ERB dari tertinggi hingga terendah

8. Menghitung nilai $A_{i}$ dan $B_{i}$ dengan rumus:

a. $A$ denganrumus:

$$
A_{i}=\frac{\left[E\left(R_{i}\right)-R_{R B}\right] \cdot \beta_{i}}{\sigma_{e i}^{2}}
$$

b. $B$ dengan rumus:

$$
\beta_{i}=\frac{\beta_{i}^{2}}{\sigma_{e i}^{2}}
$$

9. Menentukan cut-off point $\left(\mathrm{C}^{*}\right)$ berdasarkan nilai $C_{i}$ dengan rumus:

$$
C_{i}=\frac{\sigma_{m}^{2} \sum_{j=1}^{i} A_{j}}{1+\sigma_{m}^{2} \sum_{j=1}^{i} B_{j}}
$$

10. Menghitung besarnya proporsi dana masing-masing saham yang terpilih menjadi portofolio optimal dengan rumus:

Dimana:

$$
W_{i}=\frac{Z_{i}}{\sum_{j=1}^{k} Z_{j}}
$$

$$
Z_{i}=\frac{\beta_{i}}{\sigma_{e i}^{2}}\left(E R B_{i}-C^{*}\right)
$$

11. Menghitung expected return dan risiko portofolio:

a. Menghitung beta dan alpha portofolio dengan rumus: 


$$
\beta_{p}=\sum_{i=1}^{n} W_{i} \cdot \alpha_{i}
$$

b. Menentukan expected return portofolio dengan rumus:

$$
E\left(R_{p}\right)=\alpha_{p}+\beta_{p} . E\left(R_{m}\right)
$$

c. Menentukan risiko portofolio dengan rumus:

$$
\alpha_{p}^{2}=\beta_{p}^{2} \cdot \sigma_{m}^{2}+\left(\sum_{j=1}^{n} W_{i} \cdot \sigma_{e i}^{2}\right)^{2}
$$

12. Portofolio yang dibentuk berdasarkan model indeks tunggal dapat menjelaskan expected return dan risiko masing-masing saham.

\section{Hasil dan Pembahasan}

Menghitung nilai realized return $\left(R_{i t}\right)$ dan expected return $\left(E\left(R_{i t}\right)\right)$ masing-masing saham setiap bulannya

Tabel 1. Realized eturn $\left(\boldsymbol{R}_{\boldsymbol{i t}}\right)$ dan Expected return $\left(\boldsymbol{E}\left(\boldsymbol{R}_{\boldsymbol{i t}}\right)\right)$

\begin{tabular}{|c|l|r|c|}
\hline No. & Kode Saham & $\mathbf{R}_{\mathbf{i}}$ & $\mathbf{E}\left(\mathbf{R}_{\mathbf{i}}\right)$ \\
\hline 1 & ACES & 0,8713 & 0,0115 \\
\hline 2 & ADRO & 0,4925 & 0,0065 \\
\hline 3 & ANTM & 1,9085 & 0,0251 \\
\hline 4 & ASII & 0,1251 & 0,0016 \\
\hline 5 & BBCA & 1,0543 & 0,0139 \\
\hline 6 & BBNI & 0,4522 & 0,0059 \\
\hline 7 & BBRI & 0,9465 & 0,0125 \\
\hline 8 & BBTN & 1,0770 & 0,0142 \\
\hline 9 & BMRI & 0,5090 & 0,0067 \\
\hline 10 & BTPS & 1,0717 & 0,0346 \\
\hline 11 & CPIN & 0,7721 & 0,0102 \\
\hline No. & Kode Saham & $\mathbf{R}_{\mathbf{i}}$ & $\mathbf{E}\left(\mathbf{R}_{\mathbf{i}}\right)$ \\
\hline 12 & ERAA & 2,2849 & 0,0301 \\
\hline 13 & EXCL & $-0,5360$ & $-0,0071$ \\
\hline 14 & GGRM & $-0,1967$ & $-0,0026$ \\
\hline 15 & HMSP & $-0,4551$ & $-0,0060$ \\
\hline 16 & ICBP & 0,6183 & 0,0081 \\
\hline 17 & INCO & 1,2190 & 0,0160 \\
\hline 18 & INDF & 0,0609 & 0,0008 \\
\hline 19 & INKP & 3,5933 & 0,0473 \\
\hline 20 & INTP & $-0,1031$ & $-0,0014$ \\
\hline 21 & JPFA & 0,9853 & 0,0130 \\
\hline 22 & KLBF & 0,0076 & 0,0001 \\
\hline 23 & MNCN & $-0,2841$ & $-0,0037$ \\
\hline 24 & PGAS & $-0,6460$ & $-0,0085$ \\
\hline 25 & PTBA & 0,5616 & 0,0074 \\
\hline 26 & SMGR & 0,0125 & 0,0002 \\
\hline 27 & TLKM & 0,2105 & 0,0028 \\
\hline & & & \\
\hline
\end{tabular}




\begin{tabular}{|l|l|l|l|}
28 & TOWR & 0,4245 & 0,0056 \\
\hline 29 & UNTR & 0,4118 & 0,0054 \\
\hline 30 & UNVR & 0,2164 & 0,0028 \\
\hline
\end{tabular}

Berdasarkan Tabel 1. dapat dilihat nilai Realized return $\left(\mathrm{R}_{\mathrm{i}}\right)$ atau nilai tingkat jumlah keuntungan tertinggi bulan September 2014 - Januari 2021 pada saham INKP (Indah Kiat Pulp \& Paper Tbk.) sebesar 3,5933 sedangkan keuntungan bahwa data saham individual yang memiliki data saham individual yang memiliki jumlah keuntungan terendah berada pada saham PGAS (Perusahaan Gas Negara Tbk.) sebesar -0,6460. Dan dari tingkat keuntungan yang diharapkan $\left(\mathrm{E}\left(\mathrm{R}_{\mathrm{i}}\right)\right)$ bernilai positif yaitu $\left(\mathrm{E}\left(\mathrm{R}_{\mathrm{i}}\right)\right)>0$ diikutsertakan dalam analisis selanjutnya.

Menghitung nilai realized return pasar $\left(\mathbf{R}_{M}\right)$ dan expected return $\left(\mathbf{E}\left(\mathbf{R}_{M}\right)\right)$ berdasarkan IHSG bulanan.

Nilai tingkat keuntungan pasar $\left(\mathrm{R}_{\mathrm{M}}\right)$ yaitu 0,1971 . dan perhitungan tingkat keuntungan yang diharapkan pasar $\left(\mathrm{E}\left(\mathrm{R}_{\mathrm{M}}\right)\right)$ diperoleh yaitu sebesar 0,00256 .

\section{Menghitung beta dan alpha masing-masing saham}

Tabel 2. Nilai Alpha dan Beta setiap Saham

\begin{tabular}{|c|l|c|c|}
\hline No. & Kode Saham & Alpha & \multicolumn{1}{l|}{ Beta } \\
\hline 1 & ACES & 0,0088 & 1,0355 \\
\hline 2 & ADRO & 0,0029 & 1,3702 \\
\hline 3 & ANTM & 0,0201 & 1,9467 \\
\hline 4 & ASII & $-0,0023$ & 1,5071 \\
\hline 5 & BBCA & 0,0114 & 0,9650 \\
\hline 6 & BBNI & 0,0008 & 1,9965 \\
\hline 7 & BBRI & 0,0086 & 1,4951 \\
\hline 8 & BBTN & 0,0086 & 2,1576 \\
\hline 9 & BMRI & 0,0028 & 1,4947 \\
\hline No. & Kode Saham & Alpha & Beta \\
\hline 10 & BTPS & 0,0319 & 1,6417 \\
\hline 11 & CPIN & 0,0074 & 1,0822 \\
\hline 12 & ERAA & 0,0257 & 1,6642 \\
\hline 13 & EXCL & $-0,0100$ & 1,1505 \\
\hline 14 & GGRM & $-0,0049$ & 0,8887 \\
\hline 15 & HMSP & $-0,0087$ & 1,0311 \\
\hline 16 & ICBP & 0,0068 & 0,4984 \\
\hline 17 & INCO & 0,0124 & 1,4150 \\
\hline 18 & INDF & $-0,0012$ & 0,7666 \\
\hline 19 & INKP & 0,0434 & 1,5144 \\
\hline 20 & INTP & $-0,0049$ & 1,3696 \\
\hline 21 & JPFA & 0,0073 & 2,1838 \\
\hline 22 & KLBF & $-0,0020$ & 0,8243 \\
\hline 23 & MNCN & $-0,0086$ & 1,8856 \\
\hline 24 & PGAS & $-0,0148$ & 2,4111 \\
\hline 25 & PTBA & 0,0041 & 1,2537 \\
\hline 26 & SMGR & $-0,0039$ & 1,5834 \\
\hline & & & \\
\hline
\end{tabular}




\begin{tabular}{|l|l|l|l|}
27 & TLKM & 0,0008 & 0,7529 \\
\hline 28 & TOWR & 0,0042 & 0,5159 \\
\hline 29 & UNTR & 0,0033 & 0,8030 \\
\hline 30 & UNVR & 0,0018 & 0,4230 \\
\hline
\end{tabular}

Berdasarkan Tabel 2. saham yang memiliki nilai alpha tertinggi berada pada saham INKP (Indah Kiat Pulp \& Paper Tbk.) sebesar 0,0434 sedangkan saham yang memiliki nilai alpha terendah berada pada saham PGAS (Perusahaan Gas Negara Tbk.) sebesar -0,0148. Untuk saham yang memiliki nilai beta tertinggi berada pada saham PGAS (Perusahaan Gas Negara Tbk.) sebesar 2,4111 sedangkan saham yang memiliki nilai beta terendah berada pada saham UNVR (Unilever Indonesia Tbk.) sebesar 0,4230.

\section{Menghitung risiko investasi dan Menentukan return bebas risiko}

Dari perhitungan return tersebut diperoleh bahwa rata-rata SBI sebesar 0,0046 atau 0,46\% per bulan. Berikut adalah hasil perhitungan return aset bebas risiko:

Tabel 3. Menghitung Risiko Total Masing-masing Saham dan Nilai Tingkat Keuntungan yang diharapkan $\left(\boldsymbol{E}\left(\boldsymbol{R}_{i}\right)\right)$ dengan Return Aset Bebas Risiko $\left(\boldsymbol{R}_{\boldsymbol{B} \boldsymbol{R}}\right)$ Masing-masing Saham

\begin{tabular}{|c|c|c|c|c|c|}
\hline No. & Kode Saham & $\sigma_{e i}^{2}$ & $\mathbf{E}(\mathbf{R i})$ & & $\left(\boldsymbol{R}_{B R}\right)$ \\
\hline 1 & ACES & 0,0083 & 0,0115 & $>$ & \multirow{8}{*}{0,0046} \\
\hline 2 & ADRO & 0,0129 & 0,0065 & $>$ & \\
\hline 3 & ANTM & 0,0313 & 0,0251 & $>$ & \\
\hline 4 & ASII & 0,0069 & 0,0016 & $<$ & \\
\hline 5 & BBCA & 0,0026 & 0,0139 & $>$ & \\
\hline 6 & BBNI & 0,0105 & 0,0059 & $>$ & \\
\hline 7 & BBRI & 0,0063 & 0,0125 & $>$ & \\
\hline 8 & BBTN & 0,0202 & 0,0142 & $>$ & \\
\hline No. & Kode Saham & $\sigma_{e i}^{2}$ & $\mathbf{E}(\mathbf{R i})$ & & \multirow{18}{*}{0,0046} \\
\hline 9 & BMRI & 0,0058 & 0,0067 & $>$ & \\
\hline 10 & BTPS & 0,0170 & 0,0346 & $>$ & \\
\hline 11 & CPIN & 0,0125 & 0,0102 & $>$ & \\
\hline 12 & ERAA & 0,0370 & 0,0301 & $>$ & \\
\hline 14 & GGRM & 0,0053 & $-0,0026$ & $<$ & \\
\hline 13 & EXCL & 0,0122 & $-0,0071$ & $<$ & \\
\hline 15 & HMSP & 0,0072 & $-0,0060$ & $<$ & \\
\hline 16 & ICBP & 0,0038 & 0,0081 & $>$ & \\
\hline 17 & INCO & 0,0226 & 0,0160 & $>$ & \\
\hline 18 & INDF & 0,0055 & 0,0008 & $<$ & \\
\hline 19 & INKP & 0,0312 & 0,0473 & $>$ & \\
\hline 20 & INTP & 0,0097 & $-0,0014$ & $<$ & \\
\hline 21 & JPFA & 0,0244 & 0,0130 & $>$ & \\
\hline 22 & KLBF & 0,0041 & 0,0001 & $<$ & \\
\hline 23 & MNCN & 0,0226 & $-0,0037$ & $<$ & \\
\hline 24 & PGAS & 0,0222 & $-0,0085$ & $<$ & \\
\hline 25 & PTBA & 0,0158 & 0,0074 & $>$ & \\
\hline
\end{tabular}


Keterangan:

\begin{tabular}{|l|l|l|l|l|}
26 & SMGR & 0,0103 & 0,0002 & $<$ \\
\hline 27 & TLKM & 0,0039 & 0,0028 & $<$ \\
\hline 28 & TOWR & 0,0081 & 0,0056 & $>$ \\
\hline 29 & UNTR & 0,0074 & 0,0054 & $>$ \\
\hline 30 & UNVR & 0,0036 & 0,0028 & $<$ \\
\hline
\end{tabular}

Hijau = Tertinggi

Merah $=$ Terendah

Sehingga dari Indeks IDX30 untuk 30 saham yang termasuk analisis selanjutnya yaitu menjadi 18 saham.

\section{Menghitung excess return to beta (ERB)}

Tabel 4. Nilai ERB $\boldsymbol{A}_{\boldsymbol{i}}, \boldsymbol{B}_{\boldsymbol{i}}, \boldsymbol{C}_{\boldsymbol{i}}$ dan $\mathrm{C}^{*}$

\begin{tabular}{|c|l|r|r|r|r|}
\hline No. & Kode Saham & ERB & $\boldsymbol{A}_{\boldsymbol{i}}$ & $\boldsymbol{B}_{\boldsymbol{i}}$ & $\boldsymbol{C}_{\boldsymbol{i}}$ \\
\hline 1 & ACES & 0,0066 & 0,7035 & 106,8103 & 0,0010 \\
\hline 2 & ADRO & 0,0013 & 0,1957 & 145,9984 & 0,0003 \\
\hline 3 & ANTM & 0,0105 & 1,2716 & 120,9412 & 0,0018 \\
\hline 4 & BBCA & 0,0096 & 3,4481 & 360,5277 & 0,0036 \\
\hline 5 & BBNI & 0,0007 & 0,2475 & 378,3532 & 0,0003 \\
\hline 6 & BBRI & 0,0052 & 1,8485 & 353,868 & 0,0019 \\
\hline 7 & BBTN & 0,0044 & 1,0192 & 230,8253 & 0,0012 \\
\hline 8 & BMRI & 0,0014 & 0,5265 & 383,2081 & 0,0005 \\
\hline 9 & BTPS & 0,0185 & 2,9402 & 158,9591 & 0,0039 \\
\hline 10 & CPIN & 0,0051 & 0,4773 & 93,6419 & 0,0007 \\
\hline
\end{tabular}

saham yang memiliki nilai $\mathrm{C}_{\mathrm{i}}$ tertinggi yaitu saham BTPS (Bank BTPN Syariah Tbk.) sebesar 0,0039 nilai tersebut adalah nilai cut off point $\left(\mathrm{C}^{*}\right)$. Dari 18 saham, hanya ada 11 saham yang nilai ERB > Ci dimana saham-saham tersebut yang terpilih dalam pembentukan portofolio optimal yang diurutkan dari ERB yang tertinggi sampai ke yang terendah yaitu INKP, BTPS, ERAA, ANTM, BBCA, INCO, ICBP, ACES, BBRI, CPIN dan BBTN.

Menghitung besarnya proporsi dana masing-masing saham yang terpilih menjadi portofolio optimal dan Menghitung expected return pada risiko portofolio

Tabel 5. Perhitungan Proporsi Dana Masing-masing Saham dan Menentukan beta dan alpha portofolio

\begin{tabular}{|c|l|c|c|c|c|c|c|c|c|}
\hline No. & $\begin{array}{c}\text { Kode } \\
\text { Saham }\end{array}$ & $\begin{array}{c}\text { Beta } \\
\left(\boldsymbol{\beta}_{\boldsymbol{i}}\right)\end{array}$ & $\boldsymbol{\sigma}_{\boldsymbol{e} \boldsymbol{i}}^{2}$ & $\mathbf{E R B}$ & $\boldsymbol{Z}_{\boldsymbol{i}}$ & $\boldsymbol{W}_{\boldsymbol{i}}$ & $\begin{array}{c}\text { Alpha } \\
(\boldsymbol{\alpha p})\end{array}$ & $\begin{array}{c}\text { Beta } \\
(\boldsymbol{\beta p})\end{array}$ & $\boldsymbol{\sigma}_{\boldsymbol{e p}}^{\mathbf{2}}$ \\
\hline 1 & INKP & 1,5144 & 0,0312 & 0,0282 & 1,1803 & 0,1661 & 0,0072 & 0,2516 & 0,0052 \\
\hline 2 & BTPS & 1,6417 & 0,0170 & 0,0185 & 1,4178 & 0,1995 & 0,0064 & 0,3276 & 0,0034 \\
\hline 3 & ERAA & 1,6642 & 0,0370 & 0,0153 & 0,5142 & 0,0724 & 0,0019 & 0,1204 & 0,0027 \\
\hline 4 & ANTM & 1,9467 & 0,0313 & 0,0105 & 0,4138 & 0,0582 & 0,0012 & 0,1134 & 0,0018 \\
\hline 5 & BBCA & 0,9650 & 0,0026 & 0,0096 & 2,1335 & 0,3003 & 0,0034 & 0,2897 & 0,0008 \\
\hline 6 & INCO & 1,4150 & 0,0226 & 0,0081 & 0,2626 & 0,0370 & 0,0005 & 0,0523 & 0,0008 \\
\hline 7 & ICBP & 0,4984 & 0,0038 & 0,0070 & 0,4093 & 0,0576 & 0,0004 & 0,0287 & 0,0002 \\
\hline 8 & ACES & 1,0355 & 0,0083 & 0,0066 & 0,2819 & 0,0397 & 0,0003 & 0,0411 & 0,0004 \\
\hline
\end{tabular}




\begin{tabular}{|c|l|r|r|r|r|r|r|r|c|}
9 & BBRI & 1,4951 & 0,0063 & 0,0052 & 0,3243 & 0,0456 & 0,0004 & 0,0682 & 0,0003 \\
\hline 10 & CPIN & 1,0822 & 0,0125 & 0,0051 & 0,1075 & 0,0151 & 0,0001 & 0,0164 & 0,0002 \\
\hline 11 & BBTN & 2,1576 & 0,0202 & 0,0044 & 0,0601 & 0,0085 & $7,3 \mathrm{E}-05$ & 0,0183 & 0,0002 \\
\hline
\end{tabular}

proporsi dana masing-masing saham berturut-turut yaitu BBCA sebesar 30,03\%, BTPS sebesar 19,95\%, INKP sebesar 16,61\%, ERAA sebesar 7,24\%, ANTM sebesar 5,82\%, ICBP sebesar 5,76\%, BBRI sebesar 4,56\%, ACES sebesar 3,97\%, INCO sebesar 3,70\%, CPIN sebesar $1,51 \%$ dan BBTN sebesar $0,85 \%$. Dan nilai alpha portofolio diperoleh sebesar 0,0218 atau $2,18 \%$. Apabila ada perubahan return pasar yang berupa peningkatan atau penurunan maka tidak berpengaruh terhadap return saham individual. Sedangkan nilai beta portofolio diperoleh sebesar 1,3276 dimana dapat diartikan apabila ada return pasar meningkat sebesar satu satuan, maka aka nada peningkatan return pasar sebanyak 1,3276 satuan.

Portofolio yang dibentuk berdasarkan model indeks tunggal dapat menjelaskan expected return dan risiko masing-masing saham didapat sebesar 0,0252 atau 2,52\%. Hasil return portofolio tersebut diatas tingkat pengembalian pasar $\left(\mathrm{E}\left(\mathrm{R}_{\mathrm{M}}\right)\right)$ yaitu sebesar 0,0026 atau $0,26 \%$ dan diatas tingkat return bebas risiko yaitu 0,0046 atau $0,46 \%$ per bulan cukup menjanjikan. selanjutnya menghitung risiko portofolio didapat risiko portofolio saham sebesar 0,0186 atau $1,86 \%$. Dari saham pilihan tersebut diharapkan memiliki tingkat pengembalian sebesar $0,26 \%$ dan risiko yang harus dihadapi dari hasil berinvestasi pada portofolio yaitu sebesar $1,86 \%$. Risiko yang diperoleh setelah pembentukan portofolio optimal ini lebih kecil dibandingkan dengan berinvestasi dengan saham individual.

\section{Kesimpulan}

Berdasarkan saham-saham yang termasuk Indeks IDX30 dari penelitian ini dalam pembentukan portofolio optimal dengan menggunakan model indeks tunggal, maka dapat diambil kesimpulan sebagai berikut:

Pembentukan portofolio optimal dengan model indeks tunggal yang diaplikasikan pada data harga saham indeks IDX30 terdiri dari 30 saham selama periode November 2020 - Januari 2021 yang masuk pada kategori optimal yaitu 11 saham. Proporsi dana masing-masing saham berturut-turut yaitu BBCA sebesar Rp. 30.025.989, BTPS sebesar Rp. 19.954.369, INKP sebesar Rp. 16.611.983, ERAA sebesar Rp. 7.236.319, ANTM sebesar Rp. 5.823.753, ICBP sebesar Rp. 5.761.152, BBRI sebesar Rp. 4.563.673, ACES sebesar Rp. 3.967.331, INCO sebesar Rp. 3.696.074, CPIN sebesar Rp. 1.513.449 dan BBTN sebesar Rp. 845.917. Serta tingkat keuntungan yang diharpkan expected return portofolio sebesar 2,52\%.

\section{Acknowledge}

Terima kasih kepada kedua orang tua yang telah memberikan dukungan secara moral maupun materi, serta selalu menjadi penyemangat, pengingat dan pembimbing. Terima kasih kepada dosen pembimbing serta tenaga didik Program Studi Statistika Unisba untuk ilmu, pengetahuan dan dukungannya. Terima kasih juga untuk seluruh keluarga besar tanpa terkecuali, serta temanteman dan orang-orang terdekat yang selalu memberikan do'a serta semangat.

\section{Daftar Pustaka}

[1] Bank Indonesia. Suku Bunga Sertifikat Bank Indonesia. https://www.bi.go.id/id/ moneter/operasi/suku-bunga-sbi/Default.aspx. Di akses pada tanggal 05 Januari 2021

[2] Bursa Efek Indonesia. 2020. Indeks Saham. https://www.idx.co.id/data-pasar/datasaham/indeks-saham/ .Di akses pada tanggal 21 Desember 2020

[3] Handini, Sri dan Astawinetu, Erwin Dyah. 2020. Teori Portofolio Dan Pasar Modal Indonesia. Surabaya: Scopindo Media Pustaka.

[4] Muklis, Faiza. 2016. Perkembangan dan Tantangan Pasar Modal Indonesia. Jurnal Lembaga Keuangan dan Perbankan, Vol. 1, No.1, Hal: 66-67.

[5] Paramitasari, Ratih dan Mulyono. 2015. Analisis Portofolio Untuk Menentukan Expected Return Optimal dan Risiko Minimal pada Saham Perusahaan Telekomunikasi yang 
Terdaftar di Bursa Efek Indonesia. Jurnal Manajemen dan Organisasi. Vol. VI, No.1, Hal: 20-21.

[6] Sari, Firdani Antika dan Nuzula, Nila Firdausi. 2017. Pembentukan Portofolio Optimal Dengan Model Indeks Tunggal (Studi Pada Perusahaan Property, Real Estate And Building Construction Yang Tercatat Di Bursa Efek Indonesia Periode 2013-2015). Jurnal Administrasi Bisnis, Vol. 45, No.1, Hal: 2-5.

[7] Sudirman. 2015. Pasar Modal dan Manajemen Portofolio. Makassar: Sultan Amai Press.

[8] Tandelilin, Eduardus. 2010. Analisis Investasi dan Manajemen Portofolio Edisi Pertama. Yogyakarta: BPFE Universitas Gadjah Mada.

[9] Tannadi, Belvin dan Friendy. 2019. Ilmu Saham. Binjai: PT Elex Media Komputindo.

[10] Yuliati. 2011. Analisis Pembentukan Portofolio Optimal Pada Saham LQ 45 Dan JII di Busra Efek Indonesia Dengan Metode Cut Of Point. Manajemen. Fakultas Ekonomi Dan Bisnis. Universitas Islam Negeri Syarif Hidayatullah Jakarta.

[11] Zabdi, Aria dan Pandu, Dian. 2017. Pusat Edukasi Dan Informasi Pasar Modal di Yogyakarta. http://e-journal.uajy.ac.id/2992/3/2TA12017.pdf. Di akses pada tanggal 06 Januari 2021 